\title{
Procedure Dose Form
}

National Cancer Institute

\section{Source}

National Cancer Institute. Procedure Dose Form. NCI Thesaurus. Code C117521.

The form in which active and/or inert ingredient(s) of the procedure are physically presented. 